\title{
The Individual Art of Speaking Well \\ - teaching it by means of group and project work
}

\author{
Henrik Juel, Associate Professor, ph.d. Communication Studies, Roskilde University
}

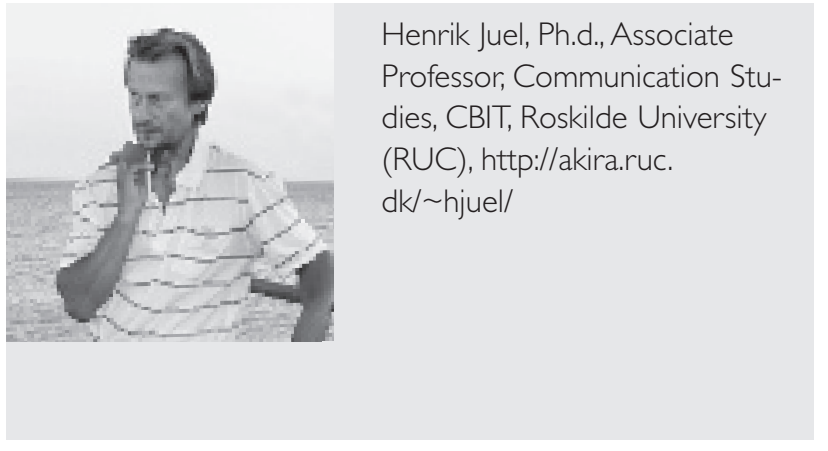

\section{Reviewed article}

Based on experimental workshops in rhetoric and free public speaking involving student performance at Speaker's Corner, London, this article argues that a focus on highly individual skills is compatible with group work and socio-cultural learning principles. The author maintains that collective responsibility may inspire the peak performance of the individual.

\section{The challenge}

At the Communication Studies of Roskilde University, we are a team engaged in teaching rhetoric, speech and oral presentation. In recent years, we have developed a way of teaching the highly individual art and craft of speaking well in front of an audience by means of socio-cultural learning principles, group and project work stressing the importance of collective responsibility, and workshops in which students are teaching students. We have put our teaching methods to the test by asking: After just three weeks of preparations in Roskilde, can we then bring our workshop of rhetoric students to England, and make them get up on a box at Speaker's Corner in London to deliver a speech? It should be their own personal speech on a topic which they themselves find most relevant for today. Will they dare? Will they be able to stand the heat at this historic - and still very lively - forum of free public speaking?

In September, 2005, we went, for the first time, to Speaker's Corner in London's Hyde Park with twenty- five students from Roskilde University, and let them try their hand at a demanding discipline: speaking from a beer crate in front of a vociferously critical, thoroughly inquisitive and culturally complex audience. In September 2006, 2007, and 2009, we repeated the experiment with 18, 26 and 20 other newly drilled rhetoric students, who tackled it with equal enthusiasm.

Each time our students have welcomed this opportunity to try out their newly acquired skills. Though many at first have feared the very thought of entering this demanding and renowned rhetorical arena, we have prepared them well, and each time we have had a $100 \%$ participation at the final trial a Sunday in the park. All have dared and all have passed "the test $"$.

In this article,${ }^{1}$ I shall expand on the preparations, the didactics and the perspectives ${ }^{2}$ revealed by these experiments in teaching free speech.

\section{Why these experiments?}

The trips to Speaker's Corner and elsewhere - we have also tried out Berlin, Copenhagen and locally Roskilde - are one facet of an intensive workshop in verbal communication at our university - and at the same time an experiment. The trips are not mandatory and not part of the normal curriculum, and the teachers have so far been working for free during the trips.

Many of the students enrolled for this course are quite unused to making a speech or standing up in front of a crowd; several are nervous of standing up just to say something in class, in front of their fellow students.Yet after just three weeks of work on rhetoric, they have to overcome the challenge: Speak for ten minutes on a subject you have chosen yourself and which you consider important; at Speaker's Corner, in English. And you must be able to get through to your audience, regardless of what sort of audience that may be!

The aim of our workshop course is not merely to enable each individual to survive a firestorm such as that at Hyde Park: it is to draw attention to the process itself, whereby one works up a speech from the 


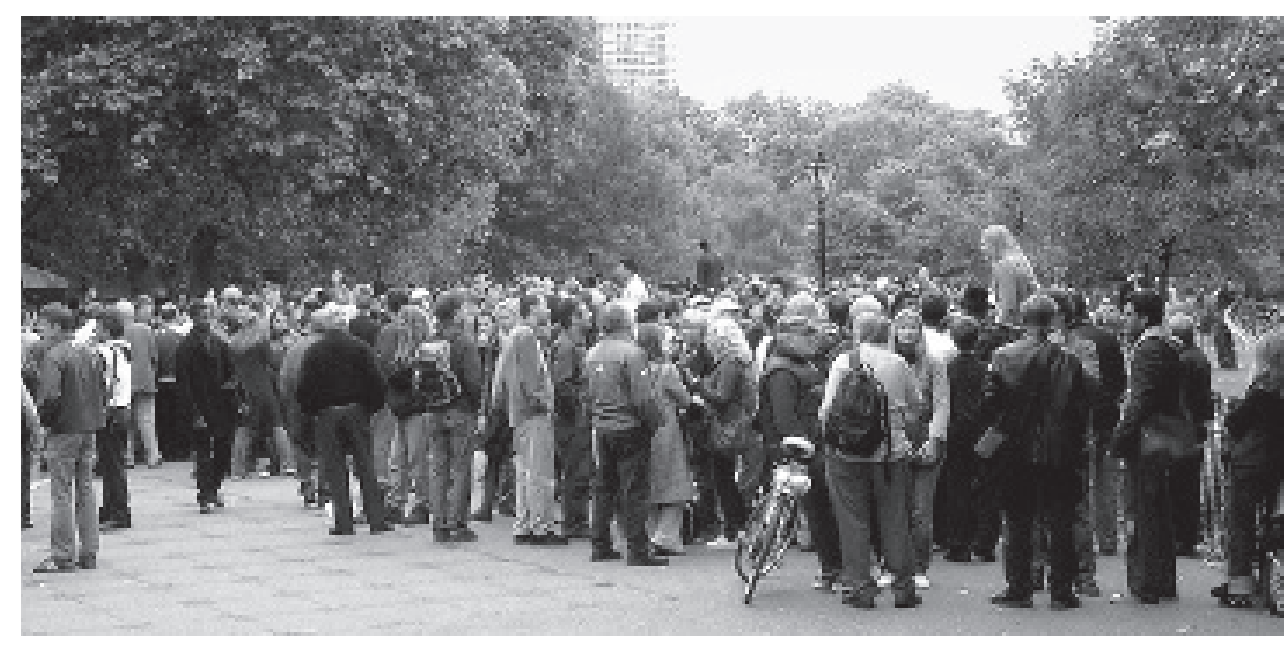

Figur 1: Speaker's Corner, Hyde Park, London. In the foreground on the left is Astrid, a blond rhetoric student from Roskilde University, Denmark, making her speech standing on a beer crate to a demanding crowd of hecklers, fanatics and Sunday walk passers-by (Photo: Jacob Reenberg, 2005).

first inkling of an idea, through the research stage and rehearsal to the final performance. By focussing on the rhetorical work process we can demonstrate that it is not reserved to those few born with nerves of steel and a silver spoon in their mouths to take the stage at a public assembly: it is really a question of rhetorical insight, of recognising the tools of rhetoric; and of practice in using them expediently. At the same time an insight into the power of your own voice and character - or ethos, ${ }^{3}$ to use a term from classical rhetoric.

\section{Speaking for real - not just for the school}

The most important thing is not having a good speech in your head - and certainly not having it down on paper - but managing the situation with enough skill to conjure up a meaningful form of communication with the audience. Rhetorically speaking, the successful speech is that which offers insights to all those participating, the speaker as well as the audience. ${ }^{4}$ Communication - and by that we mean genuine communication and not just a show of words - is essentially a personal investment for all parties involved. Ideally, you must be prepared to exchange views and to change your own views and even your horizon. In this way speaking well is more than just delivering an established and static message, it is engaging in a search for the best possible expressions, arguments and insights. ${ }^{5}$ This progressive hermeneutic principle has been well explained by Hans-Georg Gadamer and Paul Ricoeur ${ }^{6}$ among others, but most often, the focus has been on the audience, on the reader. We bring it to bear on the speaker as well believing that we are here in line with the best of rhetorical tradition: you mean what you say, and you are what you say; words and person are inseparable.

For those taking part, as well as for us as teachers, the experiences at Speaker's Corner are a thoughtprovoking manifestation of free speech. Sunday sessions in Hyde Park can give the effect of being rough, crude play - of bandying with 'freedom of expression' - but they are actually giving expression to a singular form of culture and tradition. Here a special form of speechmaking thrives in a very lively and critical debating forum. Here personal commitment thrives, side by side with physical proximity, and sets the information society's otherwise so smoothly mediated forms of communication in relief. Here one can be challenged by a shout from a stooped, evil-smelling down-and-out wearing a filthy T-shirt and holding a strong beer in one hand - but look out! - the chap may be a skilled psychiatrist, razor-sharp in both glance and critique. So here much is demanded of you if you wish to speak your mind, hang on to your ideas and insist on fighting your way through.

\section{Basic principles of Communication Studies at Roskilde University}

At Roskilde University, each student must first undergo a two-year foundation course either in the humanities, or in social science, or in natural science. ${ }^{7}$ Common to these foundation courses - despite their widely disparate subjects - is that specific project and group oriented way of working and teaching. The students largely organise their own work: only half of it is based on preparatory reading and lectures. The rest of the time is used on various projects requiring research, or perhaps on empirical work in the field taking interviews or making investigations - in which theory, method and results must all be taken thoroughly into account from beginning to end of the final written report. Typically this report is then defended by the group at an oral examination (group exams have in recent years been banned by the Danish government, but our students continue working in groups; at the actual exam they now have to appear individually explaining the joint project).

Oral expression and rhetoric are seldom addressed directly as themes, either during the foundation 
courses or the higher courses that build on them, but during the semester and in project work there is nonetheless a great deal of really practical training. One holds problem-definition seminars using other students and teachers as critics and respondents; holds group discussions; and lays out the provisional conclusions and results for one's tutor several times. In this way the students at project-oriented universities quickly pack some of the traditional skills of rhetoric in their knapsacks. The oral aspects themselves are not systematically taught, however, and e.g. voice training is unheard of.

By the time we rhetoric teachers meet the students they have, in fact, been a couple of years at university and have just started on advanced communications studies. The first thing they are exposed to in these is an intensive three-week workshop, where all the students work practically (and productively) within a specific medium. The medium can be Video, Webdesign, Exhibition, Print Media, Oral Communication, and so on.

A practical and intensive workshop such as this, making one's own material in a single medium, is thought of in educational terms as a flexible route into the more theoretical considerations underlying the study of communications: about audience groups, organisation theory, reception theory and qualitative methods. Between the two workshops lies a course in communications theory, and later the student writes a project with its starting point in a theoretical problem taken from the last workshop. That project counts towards the final examination result. To sum up the didactic principles of this education ${ }^{8}$ in various media and various forms of communication is to focus on project work, group work, producing your own media text (or communication product), and to test your product empirically on an actual audience that should be close to the intended target group.

\section{Workshop teaching in oral communications - personalities and possibilities}

Teaching oral communication or "Speech« resembles that in the other intensive workshops, each of which has its own medium - but there is, nonetheless, a notable difference in that the medium in this case is the student's own voice and person. One can distance oneself from the words one has set down on paper, from the layout that one has suggested now being projected onto a screen, and yes, one does not even need to be there when the product is handed over to the user. But one cannot walk away like that from one's own spoken performance, one cannot leap out of one's skin - or one's situation (although it is, perhaps, precisely that one can see some convulsive attempts at among nervous speakers).

At the same time as being present as the tangible word-smith, one is also "on" in the full sense of the word. To speak is to be "on-line« and »live«. It is here and now. What is said cannot be unsaid, cannot be deleted or altered. And at the same time something new can come up while one is talking which has to be taken into account. If one does not react to interruptions and questions, or simply to the atmosphere in the room - well, communication rapidly disintegrates. Practical rhetoric is situational per se. So one must be both well-prepared and open to fresh inputs; ready to improvise in order to distil something useful from the unforeseen.

The skills demanded of a good orator are not just a matter of the possession of abstract knowledge which one can read up or study aurally, but are rather skills that one has absorbed. The students will acquire something here which is not just a matter of stock materiel (e.g. classical rhetoric's fundamental concepts), but rather a craftsman-like - or at its highest level - artistic ability. It also means that the training in the workshop becomes something very personal; it is, after all, a decidedly personal skill that needs to be developed. From time to time, strong feelings come into play: there are those who object and struggle; there are limits; but also widely different talents and opportunities to be developed. As teacher one must try from the outset to take account of each student's entire personality and of the complete spectrum of their potential. The aim is not that all shall be able to speak in the same way, but that all should become better speakers while holding on to being themselves (tempting to say that some are becoming even more »themselves" in the process!).

An oral communications workshop typically consists of fifteen students, and very often, they come from that group of relatively articulate, resourceful young people who normally, in another context, are not particularly afraid of speaking up or of taking the floor. But even during the first introductory chat and presentation that first morning of the workshop, one can, as teacher, sense a significant nervousness - some students themselves mention it - and many, when the focus is on the spoken word - one's own, mark you - become uneasy. It means going pretty close to the bone with oneself and with one another to talk, not about what we say - that we often do at the university and very critically at that - but about the way we say something: about how we stand while we speak; about how we use our hands and eyes; about the way we smile or don't smile; about whether we speak loudly or clearly enough; about whether we are credible.

As teachers, therefore, we often highlight this particular form of nervousness about oral work right from the start. Perhaps we will use an exercise in which the students have briefly to present themselves while at the same time overplaying and exaggerating nervous attitudes; for example by stammering, blushing to the roots of the hair, looking away, chattering hectically 
and so on, all according to what each one can think up. Creativity flourishes when it is pretending to be anxious, and soon brings out a good deal of humour and laughter. And it is also quite an enjoyable experience to be able to praise one's students for being 'really bad' at presenting themselves!

\section{The safe area and the personal courage}

It is very important to create a secure sense of fellowship in the workshop right from the beginning.

The students arrive with markedly different life experiences and are often all too aware of how they rank in the class. Here it is all about demonstrating that all can become better speakers, but that each should achieve this in his own way. There is no singular right way of speaking: in fact it is important to draw attention to the differences. Thomas should develop his special talent and style and Stine should cultivate her eloquence and try her hand at possibilities she never knew she had.

While possibilities are thus very individual, the work is most often carried out as a common task..$^{9}$ If one has created a sound sense of fellowship - or more precisely, a positive learning space ${ }^{10}$ - then the students can quickly assess each others' weaknesses and potential. It is about illuminating the entire spectrum - from gesticulation to argumentation. We do not run on the concept of "error « but express comment more positively: "what can you try in order to improve your ability to communicate to us as listeners? « It can be disheartening to feel that one speaks unclearly or through one's nose. Against which it can be good to be told that we listeners would very much like to hear the speaker's interesting stories and that she should therefore speak more slowly and distinctly, and serve her words up to us like chocolates on a silver tray.

We work systematically with the individual's potential by holding a series of speaking rounds. In the beginning, the topics can be along the lines of describing travel experiences or leisure pursuits, but the focus at this point is neither subject nor content, but the manner in which the presentation is delivered (which of course in turn should be suitable to the content). ${ }^{11}$ At the end of each speech, everyone in the workshop writes a short letter to the speaker about things he or she is good at. The students are thus teaching each other, and this makes sense because they are all rather experienced listeners - and very different ones. The teacher's taste and opinion is not the absolute standard here - because in rhetoric it is about reaching your audience, not just about pleasing your teacher.

The letters can deal with questions of the students' contact with the audience, their voice, their use of emphasis, their clarity and so on. Next everyone writes down (never a critique of what might be wrong, but) a concrete suggestion about what the speaker might consider improving on: perhaps looking more at the audience, using the space more effectively by moving forward, or taking longer pauses, or laying stress on particular words.

The possibilities are many and the students are glad to have such feed-back ${ }^{12}$ from their colleagues. They are often surprised to hear that what they regard as mistakes - or appalling nervousness - do not play that big a role, and that they have some perfectly manageable possibilities to work on: that improvement is within speedy reach. It does not seem hopelessly difficult, for example, to take a longer pause between sentences and to remember to draw breath. That is a much more useful approach than trying to tell oneself "Now you are going to stop being nervous!"

From time to time it also means that the students' personalities and personal boundaries get knocked quite hard. Here, plainly, one must be careful not to cross the boundaries either of therapy or the infliction of trauma: it is, after all, a professional form of university education and one course amongst others, but one gets great pleasure as a teacher from seeing hesitant young men and women develop in character and become firm of voice and mien, ready to step forward to deliver a speech: one they truly believe in and are burning to give.

\section{Common criteria for quality - beyond static evaluation}

After just a few days in the workshop the students have become quite good at observing and evaluating the others' - and their own - speaking techniques. The written feed-back from the oral exercises is also often followed up by discussion, in which everyone contributes. The starting point is the individual student's speech, but from such public coaching of a single speaker more general insights can arise into those mechanisms that typically come into play when one has to speak to an audience. From this we can work towards a general overview of the criteria for quality in oral communication.

The students are quite clear in their allocation of priority to qualitative aspects: they do not pick out the formal criteria, but talk of involvement, presence, authenticity, energy - and about the speaker being able to handle his or her role, and enjoy the situation.

In this way the building blocks of rhetorical analysis and critique turn into a clear, experience-based understanding of the interplay between speaker and audience in real life. After that we are ready to dip into the more technical aspects of rhetoric and finally prepare for events like those at Speaker's Corner.

It must be fair to say that the trips to Speaker's Corner have turned out to be a success: In quantitative terms, $100 \%$ of all students participating passed their formal workshop exam. As stated at the beginning of 
this article, $100 \%$ of all students also passed the less formal, but far more demanding "test« of actually getting up on the box at Speaker's Corner.

Speaking in more qualitative terms the performances of the students must be ranked high on the scales of rhetoric: We, their teachers, may to some extent be subjective in our evaluation, but we are also professionals. ${ }^{13}$ We can analyse and appreciate the way in which the students use their voice and breathing technique, gestures, language style, examples and metaphors and how swiftly they adapt to the situation. Judged by the reaction ${ }^{14}$ of the ever-changing audience at Speaker's Corner, our students have certainly managed to put many a topic on the agenda, to get some messages across, and to stir up debates. We have also noted very favourable reactions from some of the more regular speakers and "hecklers" at Speaker's Corner. ${ }^{15}$

From written and oral evaluations of the students participating, we see that they themselves find that they have learned more from our workshops and field trips than from conventional lectures. ${ }^{16}$ This is about understanding the conditions of public speaking today, as well as understanding rhetorical theory. They also find that they have acquired analytical as well as practical and creative skills most relevant for their academic courses in Communication Studies. In all of the evaluations, however, what stands out the most is the appreciation of the personal development, the personal skill. The joyful feeling of becoming and regarding oneself as a successful speaker is considered an achievement of the outmost importance for the future - personally as well as professionally.

That a study tour to London was included in the course was perfect. I had never believed that I should find myself standing in front of a flock of strangers, and speak with so much spirit. It was a very special and fantastic experience that I will not forget. I will be thinking of that trip whenever I speak in the future. (Anne Kristine, student 2005)

Thus, in terms of pedagogy this voluntary "test" seems to boost the individual capabilities and personalities of the students far beyond what any ordinary classroom teaching or university exam could have accomplished even though we have relied heavily on teamwork and solidarity within the group. We the supervisors have learned that group work seems to be the garden that favours the blossom of each individual when it comes to acquiring the highly personal skills of speaking well under extreme conditions.

To sum up our teaching methods may seem special, focused as they are on the skills of oral communication for university students, a rather special medium and a rather personal skill. However, this practical approach paves the way for an understanding of abstract theory and classic concepts of rhetoric. In conclusion, I want to offer the suggestion that perhaps the principles in- volved are applicable to other subject matters and other classroom situations. The following main points are at the same time principles of practical organisation and of ideal pedagogy:

\section{1) Speak, speak and speak some more}

We encourage our students to get out on the floor and to start speaking from the very first day, in a safe and supportive classroom situation. They develop their speeches and speaking capabilities by speaking out in front of their fellow students. We regard the actual performance (actio) as a way to develop ideas and eloquence (inventio and elocutio), and even to support the arrangement and memorizing of the speech (dispositio and memoria). ${ }^{17}$ Students often like to write their speeches, to have a manuscript - that is part of the heavy literary academic tradition - but we want them to be true to the spoken word - to the art and craft of speaking with the fluency of conviction.

\section{2) Communication is not what is said, but what is heard}

The audience is always the best judge of what message actually comes across in the actual situation. That is why we do not rely on standard rules, conventional schemes, or even on our own authority as teachers when it comes to evaluating and developing the quality of a speech performance. We rely on the feed-back and supportive advice from fellow students acting as a trial audience. The students learn more by teaching each other. And they learn from undertaking projects of public speaking in front of a live audience outside the classroom.

\section{3) Acknowledgement and authenticity}

We work on building up the self-confidence and character, the ethos, of our students through appreciative advice and acknowledgement of their personal skills and opinions. It is essential that the students choose the topics of their public speeches themselves and that they feel responsible for the content and form and confident in what they are trying to communicate.

\section{4) Non-competitive teamwork}

We avoid all sorts of competition and negative comparisons among the students, and we do not arrange contests. Luckily we are still allowed to run workshops in practical rhetoric at the university without having to give grades or individual marks. Instead we spark the enthusiasm and energy of the students through arranging events, projects, and speech-making field trips. The students join in for all the preparations and take on the responsibility of helping each other to the 
best possible performance - and eventually to the best possible education.

\section{5) Dialogue in democracy is the responsibility of rhetoricians}

After due training, often short but always very intensely undertaken, we may take our students out in the streets; we may take them to London, to Speaker's Corner; or we may take them to Berlin, to speak on the ruins of the Wall that once divided Europe as we did in Spring, 2007. We let them know that they have a chance to speak their heart on historic ground. And even when they perform in front of their fellow students at Showtime at our university, they take free public speaking seriously, as a way to cherish democracy through dialogue and communication.

\section{6) Individuality through co-operation}

Becoming a good speaker is a very personal and individual matter. Every student has to find his or her personal style, tone, opinion and heart. But the paradox of teaching speech is that this individuality is best nourished and developed through intensive co-operation, group work and fellowship and through the response, feed-back and advice the students give each other. It is through their common projects and challenges and their social life that they enhance each other's individuality.

\section{Noter}

1 This article is based in part on a conference paper presented by Sine Carlsen, Jody Shaw, Pernille Eisenhardt and Henrik Juel, all from Roskilde University (RUC), at the Rhetoric Society of America's conference, Seattle, May 24th 2008. Original translation by Rae Amis Duxbury, new version by Henrik Juel.

2 "The modern concept of competence comprises not only relevant knowledge and skills, but also a range of personal qualities and the ability to perform adequately and flexibly in wellknown and unknown situations". Knud Illeris in "Towards a contemporary and comprehensive theory of learning" in International Journal of Lifelong Education, 2003
3 For an easy overview and explanation of rhetorical terms confer Silva Rhetoricæ: http://humanities.byu.edu/rhetoric/Silva.htm

4 I see this as one of the lessons from Lloyd F. Bitzer's "The Rhetorical Situation", in Philosophy and Rhetoric, Vol.1. nr.1, 1968, Penn. State University Press.

5 More on rhetoric, theory of knowledge and hermeneutic in Jørgen Fafner »Retorikkens Brændpunkt« in Norsklareren, nr. 1, Oslo, 1990, p. $77 \mathrm{ff}$.

6 Hans-Georg Gadamer, Wahrheit und Methode, 1960; Paul Ricoeur, Fortolkningsteori, Vinten,1979.

7 See homepage of Roskilde University, in English: http://www. ruc.dk/ruc_en/departments/

8 A more detailed discussion of the didactic principles involved in this course can be found in Juel, Henrik »Indledning - Om den kommunikationsfaglige dygtighed og måden at udvikle den på« in: Juel, Henrik (red.): Kommunikationsfagets håndvark og teori, Handelshøjskolens Forlag, 2009.

9 More on this in Olga Dysthe: "Sociokulturelle teoriperspektiver på kundskab og læring (1.del)« in Olga Dysthe (ed.): Dialog, samspil, laring, Århus 2003.

10 For a more detailed discussion of the concept of learning space confer Jeppesen, Mai-Britt Haugaard \& Ulstrup, Eva »De dialogiske læringsrum - med plads til hjerne og hjerte« in: Juel, Henrik (red.): Kommunikationsfagets håndvork og teori, Handelshøjskolens Forlag, 2009.

11 In terms of classical rhetoric, this is working on aspects of the renowned aptum-model or pentagon of Cicero.

12 On the importance of using student feed-back see Melie Liv Kreutzfeldt "Mundtlig kommunikation og feed-back som udviklingsværktøj« in: Juel, Henrik (red.): Kommunikationsfagets håndvark og teori, Handelshøjskolens Forlag, 2009

13 For more on professional evaluation of rhetorical performance see e.g. James H. Byrns Speak for yourself, 1997, p. 40.

14 The performances at Speaker's Corner have been documented by video recordings and by individual resumes by the students and teachers involved. This material, including documentary video films on $\mathrm{dvd}$, is presented in more detail in the book Mundtlighedens Magi - retorikkens didaktik, filosofi og laringskultur by Sine Carlsen and Henrik Juel (Handelshøjskolens Forlag, 2009).

15 We have benefited from guest teaching on several occasions by the performers Tony Allen and Haiko Koo. Haiko Koo runs a radio show and a website regarding Speaker's Corner: http:// www.speakerscorner.net/

16 To secure validity, some of the questionnaires for these evaluations were designed by other colleagues not involved in rhetoric or field trips.

17 This is an experimental reversal of the traditional (literary?) order of the so-called five stages of composition in classical rhetoric. For more on the traditional order confer Brian Vickers In Defence of Rhetoric, 1988, chapter iii: "The main processes of rhetoric « or Corbett \& Connors: Classical Rhetoric for the Modern Student, 1997, p. 15 ff. 